\title{
Indicadores macroeconômicos de financeirização: metodologia de construção e aplicação ao caso do Brasil
}

Miguel Bruno*

Ricardo Caffét

\section{Resumo}

0 regime de crescimento econômico brasileiro tem sido adversamente condicionado pelos interesses da revalorização rentista dos capitais e, mais amplamente, pela lógica e natureza da acumulação financeira, atualmente potencializada em mercados globais. Não é surpreendente que um dos fatos estilizados dos últimos 20 anos no Brasil seja a permanência de taxas muito baixas e voláteis de crescimento do PIB, comparativamente aos demais países emergentes. Com base na definição e no estatuto teórico do conceito de financeirização, o presente artigo constrói indicadores para a avaliação desse fenômeno no âmbito macroeconômico. Entre outras características, a financeirização na economia brasileira destaca-se pela proeminência da renda de juros, constituindose em um padrão diverso do observado em economias avançadas.

Palavras-Chave: Regime de crescimento; financeirização; acumulação rentista; capital fixo produtivo; indicadores de financeirização

\footnotetext{
"Professor da pós-graduação da ENCE/IBGE, Professor Adjunto da FCE-UERJ e da Universidade MackenzieRio. Doutor em Economia pela École des Hautes Études en Sciences Sociales -EHESS de Paris e também Doutor em Economia pelo IE/UFRJ.

" Professor Adjunto da Faculdade de Ciências Econômicas da Universidade Federal da Bahia. PhD pela Université de Paris 13.
} 


\section{Introdução}

A existência de poupança corrente externa às firmas, realizadas pelas pessoas que vivem de rendas, tende a deprimir o investimento e, portanto, a diminuir o desenvolvimento no longo prazo.

(Kalecki)

Na economia brasileira atual, o regime de crescimento econômico tem sido adversamente condicionado pelos interesses da revalorização rentista dos capitais e, mais amplamente, pela lógica e natureza da acumulação financeira. Não é surpreendente que um dos fatos estilizados dos últimos 20 anos no Brasil seja a permanência das taxas mais baixas e voláteis de crescimento do PIB, comparativamente aos demais países em desenvolvimento.

Isto decorre do fato de que a alta finança (high finance), composta por grandes bancos e conglomerados financeiros, detentores de capital e rentistas nacionais e estrangeiros, é o segmento hegemônico, na definição proposta por Gramsci (2006). Nesta definição, enfatiza-se a dimensão institucional e ideológica da hegemonia, portanto distinta da coerção direta mediante 0 uso da força. Em outros termos, para 0 surgimento e desenvolvimento do fenômeno da financeirização são necessárias estruturas institucionais permissivas que o reproduzam no plano macroeconômico, incluindo-se aí a formatação e condução da política econômica e 0 aval do Estado, para que a acumulação financeira seja a tônica dominante com relação à acumulação de capital nos demais setores de atividade.

Neste sentido, a hegemonia das finanças no Brasil se desenvolve através das instituições que dominam ou controlam, como parte significativa do aparelho de Estado, no que concernem à tomada de decisões governamentais, incluindo a formatação da política econômica e as condições institucionais que definem e reproduzem 0 atual modelo econômico. Essa dominância financeira condiciona as características das estruturas privadas de financiamento e empréstimo, além da grande mídia como principal instrumento de divulgação e sedimentação ideológica das demandas específicas desse setor. Por esta razão, o sentido concreto dessa hegemonia financeira se expressa não apenas no elevado poder político que esses atores desfrutam frente ao Estado nacional e aos demais segmentos e setores de atividade econômica, mas também nos constrangimentos diretos que impõem a esses últimos, particularmente à indústria brasileira.

Estudos de caso mostram que, numa economia sujeita à financeirização, a taxa interna de retorno que comanda as decisões empresariais de investimento nas atividades diretamente produtivas, apresenta-se mais alta do que a normalmente observada em economias não financeirizadas. Como a rentabilidade real de referência passa a ser dada pelos mercados financeiros globais, e não pelas condições específi- 
cas da acumulação de capital industrial, que, em situações normais, poderiam operar com taxas de lucro significativamente menores, parte expressiva dos investimentos é simplesmente descartada em prol da alocação financeira das poupanças empresariais. Daí resultarem, portanto, as baixas taxas de formação bruta de capital e de poupança agregada, observadas na economia brasileira, já que os detentores de capital podem revalorizá-lo com grande facilidade e baixo risco fora das imobilizações em atividades produtivas.

Para a análise consistente desse processo, faz-se necessário o desenvolvimento de indicadores que mensurem a magnitude desse fenômeno, potencializado à escala mundial pela expansão dos mercados financeiros globais. Sem pretender esgotar as possibilidades de medida sugeridas pela literatura internacional sobre 0 tema, os indicadores propostos se adequam às limitações das bases de dados do Brasil, que são mais propícias à construção de indicadores macroeconômicos para análise do processo de financeirização.

Além dessa introdução, 0 artigo está estruturado como segue. A seção 2 discute 0 estatuto teórico do conceito de financeirização, explicitando sua relevância para as análises macroeconômicas. Na seção 3 , são propostos quatro indicadores para a mensuração e avaliação dos impactos macroeconômicos desse fenômeno. A seção 4 discute as mudanças nos padrões de financeirização a partir das transformações institucionais observadas na evolução de longo prazo da economia brasileira. Em caráter preliminar, a seção 5 aborda brevemente a problemática das relações Estado-economia num contexto estrutural marcado pela acumulação rentista e pela elevada renda de juros. 0 trabalho é concluído com a seção 6 .

\section{Estatuto teórico do conceito de financeirização}

0 fenômeno da financeirização (financialization) não é novo. Ficou consagrado pelas análises regulacionistas ${ }^{1}$ e pós-keynesianas como um processo inerente à natureza e lógica da acumulação capitalista desde que 0 capitalismo se afirmou em suas bases industriais. Os capitais, ao longo de seu ciclo reprodutivo, movem-se através de formas diferenciadas de alocação como pressupostos de sua valorização. Destacam-se sob a forma monetária; imobilizações em capital fixo e demais insumos necessários ao processo produtivo e diversos tipos de ativos financeiros não monetários presentes na base da circulação bancária. Essas diferentes formas do capital são, por sua vez, dotadas de graus diversos de liquidez, rentabilidade, risco e possibilidades de autoexpansão.

${ }_{1}^{1}$ Referem-se aos trabalhos desenvolvidos no âmbito da Teoria da Regulação, por autores como Robert Boyer, Pascal Petit, Bruno Théret e Jaime Marques-Pereira, entre outros. 
A financeirização é um fenômeno macroeconômico que tem suas expressões micro e setoriais particulares. Para que possa surgir e se desenvolver, são necessárias condições institucionais e organizacionais específicas, que lhes reproduzam macrodinamicamente. Em outros termos, a alternativa de revalorização direta dos capitais por meio da circulação financeira está sempre presente em toda a economia capitalista que possua uma base mínima de desenvolvimento bancário e financeiro. Afinal, o capital se acumula e se revaloriza não apenas sob a forma de ativos reais, produtivos ou não, mas também sob a forma de moeda, débitos e demais ativos monetários e financeiros com diferentes graus de liquidez. Entretanto, quando essa alternativa é generalizada e aprofundada, inclusive em mercados financeiros globais, os lucros não operacionais podem superar significativamente os lucros operacionais, o que torna as atividades industriais menos atrativas, exceto quando podem contar com estímulos governamentais ou financiamentos públicos que compensem os custos inerentes à imobilização.

Em termos keynesianos, a financeirização eleva a um paroxismo a preferência pela liquidez dos detentores de capital, pois as atividades industriais se veem ameaçadas pelas condições mais vantajosas ofertadas pela alocação financeira, como também, e paradoxalmente, pelas instabilidades derivadas da própria racionalidade dos mercados financeiros liberalizados. Em resumo, para a indústria, os mercados financeiros representam uma alternativa plena de ambiguidades e contradições.

De um lado, dadas às oportunidades de ganhos substanciais, fáceis e rápidos com operações financeiras, a indústria manterá montantes expressivos das poupanças empresariais (lucros retidos ou não distribuídos aos proprietários e acionistas) sob a forma de ativos financeiros e isto reduzirá o ritmo de acumulação de capital industrial, entendida como 0 crescimento do volume de máquinas, equipamentos e instalações, que permitiriam incrementar o potencial produtivo e as condições de competitividade externa da economia nacional. De outro, os mercados financeiros constituem uma ameaça, pois como as possibilidades de crises, ciclos e bolhas especulativas - que derivam da própria natureza desses mercados - estão sempre latentes, a indústria torna-se muito mais seletiva com relação às opções de investimento em ampliação da capacidade produtiva ou modernização de plantas.

Em suma, se nos períodos de estabilidade dos mercados, as facilidades de revalorização de capitais, ofertadas pela financeirização, levam as atividades produtivas a reduzir ou manter baixo o ritmo e o quantum de investimento, nos períodos de instabilidade, quando os riscos de crise financeira tornam-se máximos, estes cairão muito mais. Desta vez, porém, com a ressalva de que também os lucros não operacionais, derivados da revalorização financeira de ativos, podem tornar-se insuficientes para compensar os níveis baixos dos lucros operacionais impostos pela própria conjuntura de crise. 


\section{Definição do fenômeno e sua relevância analítica}

0 estatuto teórico do conceito de financeirização surge a partir do momento em que, no ciclo reprodutivo dos capitais, as formas monetária e financeira adquirem proeminência quantitativa (proporção elevada dos recursos alocados em ativos financeiros de alta liquidez comparativamente às imobilizações de recursos que as atividades produtivas exigem) alterando, qualitativamente, o padrão de crescimento e acumulação de capital. A financeirização está caracterizada quando as estruturas macroeconômicas permitem, estimulam e generalizam a revalorização dos capitais por meio de diferentes ativos e produtos financeiros, em detrimento do crescimento do estoque de capital fixo produtivo (máquinas, equipamentos e instalações, infraestruturas). A possibilidade de obtenção de taxas elevadas de rentabilidade real, com alta liquidez e, na maioria dos casos, com baixo grau de risco, torna-se um fator de desestímulo ao investimento produtivo, além de suscitar e promover comportamentos rentistas e aumentar a influência do setor bancário-financeiro sobre a formatação e condução da política econômica. Maior detalhamento das definições usuais da financeirização encontra-se em Bruno et al. (2011).

Para fins desse artigo, é suficiente a apreensão da financeirização como um fenômeno que pode ser detectado tanto no plano agregado ou macroeconômico quanto no plano empresarial ou da firma. Contudo, a existência e reprodução de um processo de financeirização pressupõem uma macroestrutura institucional que valide os comportamentos rentistas e a valorização dos capitais, de forma preponderante, por meio de canais financeiros e monetários. Consequentemente, em detrimento das atividades diretamente produtivas, pois estas passam a ser consideradas por demais arriscadas ou muito menos atrativas sob os critérios de risco, liquidez e rentabilidade real. Essa macroestrutura institucional integra as finanças públicas que, em geral, permanecem subordinadas aos interesses dos mercados financeiros e das classes rentistas. Como será mostrado, é essa subordinação que explica a razão pela qual o mercado financeiro passa a monitorar sistematicamente as ações dos Estados nacionais, particularmente no que concernem à formatação e condução da política econômica.

As implicações microeconômicas desse fenômeno foram analisadas em Stockhammer (2004), que mostra como a existência de um ambiente macroeconômico financeirizado condiciona as práticas de gestão empresarial, reorientando-as no sentido da redução das taxas de acumulação de capital fixo produtivo. Esse padrão de racionalidade econômica também influencia as famílias, conduzindo, em ambos os casos, a reduções substanciais das taxas de poupança empresarial e familiar. 0 ritmo de baixo crescimento do estoque de capital fixo leva a um menor crescimento econômico e, em consequência, às baixas taxas de poupança agregada. A exceção fica por conta dos países asiáticos, notadamente a China, cujas finanças, públicas e 
privadas, ainda, permanecem direcionadas para a acumulação de capital fixo, base de suas elevadas taxas de crescimento econômico.

A importância das análises setoriais para 0 estudo do fenômeno da financeirização decorre dos efeitos distributivos que esse processo provoca. No caso brasileiro, os setores ligados à produção de commodities, agronegócios e infraestrutura têm sido flagrantemente beneficiados pelas estruturas institucionais do atual modelo econômico. As atividades industriais de maior valor agregado e conteúdo tecnológico são prejudicadas pela assimetria cambial imposta pelo modelo e pelas taxas demasiadamente elevadas de juros reais. Pesquisas futuras poderão mapear os setores e ramos ganhadores e perdedores, como um expediente-chave, para a formulação de políticas industriais e políticas públicas consistentes com uma verdadeira estratégia de desenvolvimento econômico nacional.

\section{Indicadores macroeconômicos de financeirização}

Quatro principais indicadores são propostos para 0 nível macroeconômico: 1) a participação da renda de juros no produto total, frequentemente em detrimento do investimento e da formação de poupança produtiva, ${ }^{2}$ 2) a composição setorial da renda de juros; 3) a composição da receita operacional do sistema financeiro e 4) a taxa macroeconômica de financeirização. Destaque-se que os dois primeiros indicadores expressam apenas o peso dos fluxos de juros na economia, enquanto os dois últimos refletem o peso da renda financeira total, incluindo não apenas a renda de juros, mas outras rendas derivadas da detenção de ativos financeiros, tais como os dividendos.

\section{Participação da renda de juros no produto total}

A participação da renda de juros no valor adicionado total é um importante indicador macroeconômico do grau de financeirização de uma economia, notadamente, no caso brasileiro em que a renda de juros é muito significativa. Como toda renda, os fluxos de juros são deduções do valor adicionado gerado pelas atividades diretamente produtivas, que os detentores de capital recebem por direito de propriedade. Como será mostrado mais adiante, no caso específico do Brasil, a participação dos

\footnotetext{
${ }^{2}$ Segundo Aglietta (1999), a poupança improdutiva é definida como o fluxo de recursos não consumidos, que são aplicados nas transferências de propriedade entre ativos já existentes e, portanto, não financia a produção de ativos novos. Por sua vez, a poupança produtiva é aquela que é efetivamente aplicada na formação de capital fixo das empresas e do Estado.
} 
juros no PIB atinge proporções muito elevadas, convertendo-se, por analogia com a carga fiscal, em uma efetiva carga financeira sobre o produto total gerado pelas atividades não financeiras.

A análise de um processo de financeirização deve se manter em perspectiva setorial, mesmo se 0 foco for, inicialmente, o macroeconômico. A massa de lucros total da economia irá repartir-se entre as diversas frações do capital. Nesse contexto, a repartição do valor adicionado entre lucros empresariais, juros e salários passa a ser fundamental. Uma hipótese explicativa do padrão de financeirização vigente no Brasil é a de que o elevado peso da renda de juros, decorrente das elevadas taxas reais de juros praticadas domesticamente, tem contribuído para elevar o poder político e o econômico do setor financeiro e das classes rentistas, tanto sobre as atividades produtivas quanto sobre 0 aparelho de Estado.

\section{Metodologia de construção do indicador}

A metodologia de construção desse indicador considerou os fluxos de juros recebidos, pagos e apropriados pelo setor financeiro brasileiro, que foram calculados com base nos dados do Plano Contábil das Instituições do Sistema Financeiro Nacional Cosif, elaborado pelo Banco Central do Brasil. Esta base de dados fornece um mapeamento detalhado da estrutura de ativos, passivos e patrimônio líquido das empresas financeiras, além dos fluxos de receitas e despesas. Não é objetivo desse trabalho detalhar a metodologia utilizada pelo IBGE, mas, tão somente, fornecer uma perspectiva geral, que será suficiente para fundamentar o indicador proposto de financeirização.

A Coordenação de Contas Nacionais do IBGE tem acesso a base de dados do CosiF necessária para a construção das contas do setor financeiro. 0 PIB financeiro é calculado mediante 0 cômputo da receita e da despesa total de juros dos bancos e demais empresas financeiras, que são então acrescidas de outras receitas e despesas, como as provenientes das tarifas bancárias. A metodologia utilizada é a proposta pelo System of National Accounts - SNA que se baseia no cálculo dos serviços de intermediação financeira indiretamente medidos - SIFIM. A maior proporção dessa estatística, que visa mensurar a contribuição do sistema financeiro ao valor adicionado total, é composta pelo diferencial de juros recebidos e pagos pelos bancos. Duas metodologias são propostas pelo SNA. Na primeira metodologia, faz-se um inventário das contas de receitas e despesas que implicam fluxos de juros recebidos e pagos. Na segunda, recorre-se às taxas médias de juros que, uma vez aplicadas à estrutura de ativos e passivos, vão compor a renda de juros recebida e paga pelo sistema financeiro nacional. 
Os dados comumente divulgados referem-se apenas a esse diferencial, que corresponde à maior parcela do valor adicionado total apropriada pelo sistema financeiro. Entretanto, o grau de financeirização pela renda de juros não pode ser avaliado apenas pelo montante de juros apropriados pelo sistema bancário-financeiro, pois o fenômeno da financeirização manifesta-se quando agentes, classes sociais e setores, cujas atividades são não financeiras, passam a atuar ostensivamente em atividades financeiras ou rentistas. Por exemplo, as empresas não financeiras obtêm lucros não operacionais que podem superar os lucros derivados das atividades-fim.

Tabela 1 Fluxos de juros recebidos, pagos e apropriados pelo sistema bancário-financeiro brasileiro em \% do PIB (1993-2010)

\begin{tabular}{|c|c|c|c|}
\hline Ano & Juros Recebidos & Juros Pagos & Juros Apropriados \\
\hline 1993 & 37,40 & 9,81 & 27,59 \\
\hline 1994 & 32,57 & 20,19 & 12,39 \\
\hline 1995 & 28,72 & 23,07 & 5,66 \\
\hline 1996 & 21,51 & 16,75 & 4,76 \\
\hline 1997 & 19,87 & 15,31 & 4,56 \\
\hline 1998 & 23,26 & 18,67 & 4,59 \\
\hline 1999 & 42,37 & 38,14 & 4,23 \\
\hline 2000 & 18,64 & 15,04 & 3,60 \\
\hline 2001 & 29,87 & 25,31 & 4,56 \\
\hline 2002 & 34,96 & 29,91 & 5,06 \\
\hline 2003 & 29,66 & 23,99 & 5,67 \\
\hline 2004 & 30,30 & 23,17 & 7,13 \\
\hline 2005 & 32,71 & 30,23 & 2,48 \\
\hline 2006 & 34,83 & 31,66 & 3,18 \\
\hline 2007 & 33,46 & 30,48 & 2,98 \\
\hline 2008 & 28,60 & 25,69 & 2,91 \\
\hline 2009 & 24,77 & 22,08 & 2,69 \\
\hline $2010^{*}$ & 24,52 & 21,86 & 2,66 \\
\hline Média 1993-2003 & 28,98 & 21,47 & 7,52 \\
\hline Média 2004-2010 & 29,89 & 26,45 & 3,43 \\
\hline
\end{tabular}

FONTE: Sistema de Contas Nacionais - IBGE NOTA: *Dados previstos.

Os fluxos de juros são calculados pelas Contas Nacionais, de acordo com as metodologias propostas pelo System of National Accounts SNA. Os dados primários provêm da base de dados do Plano Contábil das Instituições do Sistema Financeiro Nacional-CosIF, elaborada pelo Banco Central do Brasil. 
É precisamente a parcela apropriada pelas classes rentistas e empresas não financeiras que está no cerne do processo de financeirização, por sua lógica e natureza.

A Tabela 1 mostra o fluxo total de juros recebidos e pagos pelo Sistema Financeiro brasileiro como percentagem do PIB, para o período 1993-2010, com base nos dados das Contas Nacionais do IBGE. 0 destaque fica por conta da elevada participação do fluxo recebido, 29\% do PIB para o subperíodo 1993-2003 e de 30\% entre 2004 e 2010. Praticamente, 1/3 do produto total brasileiro está sendo absorvido pela renda de juros. Essa seria uma das razões para a elevação da carga fiscal, desde os anos de 1990, uma vez que 0 Estado brasileiro precisa fazer frente à elevada carga financeira em juros que incide sobre as atividades diretamente produtivas. Do contrário, os gastos sociais teriam de ser dramaticamente reduzidos. Essa questão será melhor avaliada na próxima seção que trata das consequências da financeirização sobre 0 setor público brasileiro.

\section{Composição setorial da renda de juros}

A composição setorial dos fluxos de juros pagos e recebidos por setores de atividade econômica é um importante indicador de apropriação da renda de juros. A série das matrizes de juros elaborada pelo IBGE forneceria, com um grau muito maior de detalhamento, a totalidade desses fluxos para a economia brasileira. Todavia, essa série foi interrompida e não se dispõe mais de informações para os anos de 2000. Mas uma maneira de se contornar, parcialmente, essa lacuna, consiste na utilização das contas financeiras e de patrimônio, que integram o sistema de contas nacionais do Brasil. Nesse sentido, os percentuais dos fluxos de juros pagos e recebidos pelos cincos setores das contas nacionais fornecerão informações quanto aos setores que mais se beneficiam dessa modalidade de renda financeira.

\section{Metodologia de construção do indicador}

Este indicador é construído pelo IBGE, seguindo metodologia proposta pelo SNA para a elaboração das contas nacionais, e não há necessidade de maior detalhamento quanto à sua elaboração.

Destaque-se que, apesar de sua posição deficitária em juros (Tabela 2), as empresas não financeiras apresentam percentagens elevadas de ganhos com a renda de juros. Além disso, os fluxos de juros pagos e recebidos como percentagem do PIB brasileiro praticamente se equilibram. 
Tabela 2 Fluxos de juros recebidos, pagos e apropriados pelas empresas não financeiras (2005-2009)

\begin{tabular}{cccc}
\multicolumn{4}{c}{ Empresas Não financeiras - Fluxos em \% PIB (2005-2009) } \\
Anos & Juros Recebidos & Juros Pagos & Juros Apropriados \\
2005 & 6,87 & 8,31 & $-1,44$ \\
2006 & 7,24 & 7,67 & $-0,44$ \\
2007 & 7,56 & 7,91 & $-0,35$ \\
2008 & 7,76 & 7,83 & $-0,07$ \\
\hline
\end{tabular}

Fontes: Sistema de Contas Nacionais Brasil - Conta Financeira e Conta de Patrimônio Financeiro 2004-2009.

Tabela 3 Fluxos de juros recebidos, pagos e apropriados pelas empresas financeiras (2005-2009)

\begin{tabular}{cccc} 
Anos & $\begin{array}{c}\text { Empresas Financeiras - Fluxos em \% PIB (2005-2009) } \\
\text { Juros Recebidos }\end{array}$ & Juros Pagos & Juros Apropriados \\
\hline 2005 & 32,71 & 30,23 & 2,48 \\
2006 & 34,83 & 31,66 & 3,18 \\
2007 & 33,46 & 30,48 & 2,98 \\
2008 & 28,60 & 25,69 & 2,91 \\
2009 & 24,77 & 22,08 & 2,69 \\
\hline
\end{tabular}

Fontes: Sistema de Contas Nacionais Brasil - Conta Financeira e Conta de Patrimônio Financeiro 2004-2009.

A Tabela 3 apresenta os fluxos de juros para 0 setor bancário-financeiro, onde se pode constatar a elevada carga financeira em juros sobre 0 PIB brasileiro.

Diferentemente ocorre com 0 governo (Tabela 4), o qual se mostra muito mais deficitário em juros, com montantes atingindo a média de $-5,4 \%$ do PIB contra $-0,61 \%$ das empresas não financeiras.

0 setor famílias (Tabela 5) apresenta-se superavitário com relação à renda de juros, refletindo, como esperado, a ampla detenção de ativos financeiros conectados ao endividamento público e privado brasileiro, por parte das famílias brasileiras de mais alta renda. ${ }^{3}$

0 resto do mundo (Tabela 6), apesar de apresentar percentuais inferiores quanto aos fluxos de juros, é um recebedor líquido.

\footnotetext{
${ }^{3}$ De acordo com Pochmann, M. (Org.) et al. (2004), Atlas da Exclusão Social - Os Ricos no Brasil, as famílias mais ricas (os 10\% mais ricos do Brasil) detêm cerca de $80 \%$ dos títulos da dívida pública brasileira.
} 
Tabela 4 Fluxos de juros recebidos, pagos e apropriados pela administração pública (2005-2009)

\begin{tabular}{cccc} 
& \multicolumn{4}{c}{ Administração Pública - Fluxos em \% PIB (2005-2009) } & \\
Anos & Juros Recebidos & Juros Pagos & Juros Apropriados \\
2005 & 4,61 & 10,00 & $-5,38$ \\
2006 & 4,39 & 10,49 & $-6,10$ \\
2007 & 4,08 & 9,52 & $-5,44$ \\
2008 & 3,43 & 8,59 & $-5,16$ \\
2009 & 3,45 & 8,36 & $-4,91$ \\
\hline
\end{tabular}

Fontes: Sistema de Contas Nacionais Brasil - Conta Financeira e Conta de Patrimônio Financeiro 2004-2009.

Tabela 5 Fluxos de juros recebidos, pagos e apropriados pelas famílias (2005-2009)

\begin{tabular}{|cccc|}
\hline \multicolumn{4}{c}{ Famílias - Fluxos em \% PIB (2005-2009) } \\
\hline Anos & Juros Recebidos & Juros Pagos & Juros Apropriados \\
\hline 2005 & 5,08 & 2,21 & 2,88 \\
\hline 2006 & 5,19 & 2,82 & 2,38 \\
2007 & 5,45 & 3,11 & 2,34 \\
\hline 2008 & 6,30 & 4,38 & 1,93 \\
\hline
\end{tabular}

Fontes: Sistema de Contas Nacionais Brasil - Conta Financeira e Conta de Patrimônio Financeiro 2004-2009.

Tabela 6 Fluxos de juros recebidos, pagos e apropriados pelo resto do mundo (2005-2009)

\begin{tabular}{cccc} 
& \multicolumn{2}{c}{ Resto do Mundo - Fluxos em \% PIB (2005-2009) } \\
Jnos & Juros Recebidos & Juros Pagos & Juros Apropriados \\
2005 & 1,78 & 0,31 & 1,47 \\
2006 & 1,51 & 0,52 & 0,99 \\
2007 & 1,25 & 0,78 & 0,47 \\
2008 & 1,06 & 0,68 & 0,39 \\
2009 & 0,99 & 0,48 & 0,51
\end{tabular}

Fontes: Sistema de Contas Nacionais Brasil - Conta Financeira e Conta de Patrimônio Financeiro 2004-2009. 


\section{Composição das receitas operacionais do setor financeiro}

A análise da composição das receitas operacionais das empresas financeiras é um indicador relevante do padrão de acumulação desse setor porque permite examinar-se as principais fontes de receita, necessariamente associadas às decisões de alocação por tipo de ativo.

\section{Metodologia de construção do indicador}

Selecionam-se as principais rubricas componentes da receita operacional do setor financeiro (R0) brasileiro, constantes do Plano Contábil das Instituições Financeiras do Cosif, elaborado pelo Banco Central do Brasil. A análise gráfica da evolução dos componentes da RO permite constatar-se que as rendas de títulos e valores mobiliários (títulos financeiros públicos e privados) permanecem em tendência de crescimento desde 0 início das séries em 1995, ultrapassando os $80 \%$ da R0 no ano de 2007 . Por outro lado, destaca-se a queda de participação das rendas de operações de crédito, que, em 2007, caiu abaixo dos $10 \%$ da R0. Este fato confirma que 0 sistema bancário-financeiro brasileiro continua muito pouco funcional nesse quesito fundamental às economias capitalistas modernas. 0 provimento de crédito, cujo custo é muito elevado, comparativamente aos padrões internacionais, é flagrantemente inadequado.

\section{Gráfico 1 As rendas de títulos e valores mobiliários são a principal fonte de receitas do sistema financeiro, incluindo os fundos}

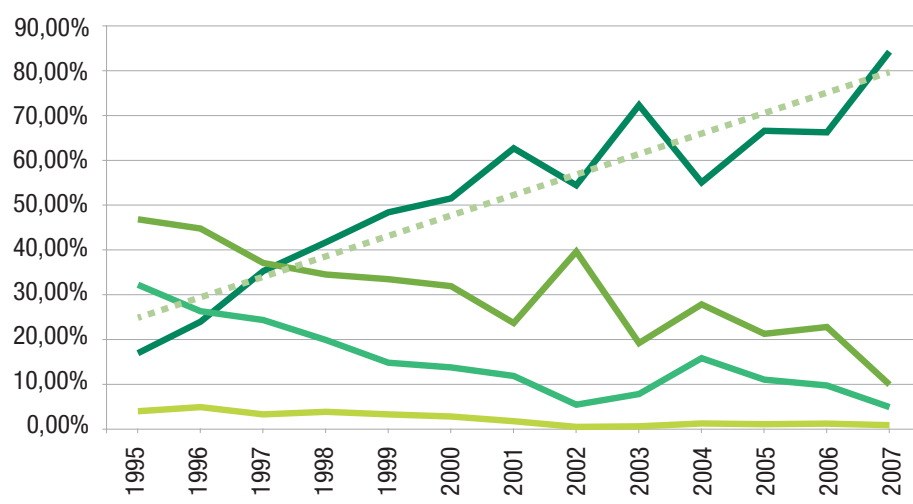

Rendas de Títulos e Valores Mobiliários

- Rendas de Arrendamento Mercantil

Outras receitas operacionais

. . . . . Linear (Rendas de Títulos e Valores Mobiliários)

Fonte: Plano Contábil das Instituições Financeiras Rendas de Operações de Crédito COSIF - BCB. 


\section{A taxa de financeirização: uma medida do grau de substituição dos ativos fixos produtivos por ativos financeiros}

Em Aglietta (1998), a taxa de financeirização é definida pela razão entre 0 estoque de ativos financeiros e 0 estoque total de ativos (reais e financeiros). Alvarez Peralta e Luengo Escalonilla (2011), com base em Husson (2008), propõem um conceito empírico para a taxa de financeirização macroeconômica, formado pela diferença entre a taxa do excedente macroeconômico e a taxa de investimento (formação bruta de capital fixo produtivo) da economia. 0 conceito foi aplicado em um grupo de países da OCDE (EU-15 Países). Sua lógica parte da hipótese de que 0 lucro não investido é principalmente distribuído sob a forma de lucros financeiros. Entretanto, este indicador relaciona dois fluxos que não mostram os fluxos derivados da repartição dos estoques de riqueza a longo prazo $0^{4}$. Um problema de natureza dinâmica surge aqui, cuja análise remete à insuficiência da financeirização, entendida apenas como uma questão de eficiência marginal do capital, enquanto lucratividade esperada comparada à taxa de juros ${ }^{5}$. Nessas condições, somente 0 nível ex-post dos investimentos é avaliado e os efeitos cumulativos do investimento em estado de "desequilíbrio" não constituem per si um movimento estabilizador da economia.

A taxa de financeirização nestes termos corre 0 risco de se tornar apenas um mecanismo eventual de "desvio" de fundos financeiros na formação real de capital, conforme Tobin (1997), ou seja, a compra de ativos financeiros em lugar de ativos produtivos não modifica a composição do produto em nível macroeconômico $0^{6} .0$ investimento financeiro é somente uma transferência de ativos, não constituindo um uso produtivo da renda. Todavia, como constatou Orhangazc (2008), este argumento é contraditório em seus próprios termos.

Assim, antes da difusão, nos anos de 1980 e 1990, de uma literatura da financeirização como um fenômeno de interesse - admitia que investimento financeiro e 0 investimento real pudessem ser substitutos, principalmente em períodos em que 0 primeiro oferece altos retornos. Como consequência, menos fundos estarão disponíveis para a formação de capital (investimento real), determinando um crowding-out do investimento real pelo investimento financeiro.

\footnotetext{
${ }^{4}$ Um dos aspectos levantados por Husson (2008) é, justamente, a presença de uma tendência autônoma da financeirização frente ao papel do financiamento à acumulação capitalista e sua separação artificial do conflito distributivo presente na repartição do valor agregado.

${ }^{5}$ Kalecki (1936), num texto de apreciação da Teoria Geral põe em evidência as dificuldades teóricas da "estática" keynesiana do ponto de vista do investimento. Assim, a decisão ex-ante dos investimentos e 0 efeito cumulativo wickselliano conduzem a situações dinâmicas que são imprevisíveis de outra forma.

${ }^{6}$ Tobin diz que as "demandas por ativos em papel" não são demandas por bens e serviços contados no PIB, nem em C, G ou I, nem em (X-M)".
} 
A refutação do argumento segundo 0 qual investimento físico não pode ser substituído por investimento financeiro tende a perder de vista os efeitos dos mercados financeiros sobre as próprias decisões de investimento ${ }^{7} .0$ diferencial decisivo - a taxa efetiva de juros - é o valor do desconto entre as taxas obtidas sobre a remuneração do capital e do crédito sobre o investimento. Quando a taxa efetiva se eleva, os custos associados às taxas de utilização aumentam, reduzindo 0 estoque de capital desejado. Desse modo, se as taxas de juros de longo prazo sobem, o custo de uso do capital também se incrementa, conduzindo a um baixo nível de investimento.

Tal possibilidade é prevista inclusive pelos modelos tipo stock-flow consistent, cujos regimes de crescimento podem incluir além de um crescimento virtuoso puxado pelas finanças ou expansões 'finance-led growth', outras dinâmicas altamente instáveis. Assim, os trabalhos de Hein (2010) e (2001) e Van Treeck (2009) reconhecem que regimes viciosos de crescimento podem também tomar lugar, suprimindo efeitos baseados em significativos $q$ de Tobin na função de investimento, gerando situações de "lucro sem investimento" e, mais ainda, regimes de acumulação de caráter contracionista sob a égide das finanças.

Como propõe Frézal (2010), um fato econômico estilizado é a medida de uma relação entre duas variáveis e não a medida de uma variável. Portanto, na comparação entre as medidas físicas e econômicas, a separação ou isolamento dos parâmetros econômicos é uma questão conexa da métrica. Não é a precisão ou subjetividade da medida que é decisiva, mas a subjetividade da métrica empregada para estabelecer uma relação entre as variáveis, quando a economia enfrenta um problema de "metamedida" ou "medida da medida". A financeirização apenas mensurada a partir de fluxos tende a mostrar a sua dimensão de transferência de propriedade de ativos e a ocultar o seu caráter de utilização da renda, que somente é vista através da formação de estoques de ativos que geram fluxos. Esses últimos vinculam estruturalmente a substituição de fluxos de investimentos físicos por investimentos financeiros.

A perspectiva analítica, anteriormente aludida, procura refutar os fatos estilizados da financeirização com base em evidências empíricas da queda da taxa de lucro macroeconômica como fator preponderante no declínio da taxa de acumulação. Nos ambientes institucionais onde prevalece 0 princípio do shareholder value, a regra financeira estabelece 0 critério "reduzir o tamanho e distribuir" frente ao "reter lucros e investir". Os exemplos notáveis na atualidade são os das economias desenvolvidas da União Europeia e, em especial, o da economia norte-americana, em que esta análise

\footnotetext{
${ }^{7}$ Em Tobin os mercados financeiros são, por hipótese, eficientes e estáveis. A "teoria q" de Tobin supõe que as firmas irão continuar a investir em ativos físicos, desde que a relação entre o valor de mercado da firma $\mathrm{e}$ o custo de substituição dos ativos de capital reprodutíveis da firma é maior do que 1.

${ }^{8}$ Nesse sentido, pode-se falar da relação matemática que estabelece as condições de proximidade e distância geométrica entre as variáveis, como uma nuvem de pontos e uma reta.
} 
mostra-se coerente. Entretanto, no contexto específico brasileiro, a orientação rentier value prevalece e as quedas da formação de ativos produtivos associam-se ao fortalecimento dos regimes de crescimento finance-led edominated accumulation regime. Neste último caso, predominam as tendências à estagnação do crescimento econômico como resultado do bloqueio da taxa de acumulação de capital fixo produtivo.

Com efeito, a taxa de financeirização como ratio de estoques surge como relação mais robusta desse processo. De modo distinto das convicções tradicionais, para as quais o investimento de longo prazo seria pouco afetado pelas mesmas incertezas que derivam das taxas de juros de curto prazo, não pode ser ignorado o fato que a volatilidade dessas taxas possui efeitos mais persistentes na economia brasileira. Contrariamente, ao argumento kaleckiano típico, segundo o qual as taxas de juros de longo prazo são, supostamente, mais estáveis, essas últimas não escapam à dinâmica câmbio-juros, que envolve dimensões de inconversibilidade específicas do regime monetário nacional ${ }^{9}$. Desse modo, as taxas de juros elevadas do "curto longo prazo", em que pese seu significativo declínio relativo, refletem esta instabilidade macroeconômica fundamental. Consequentemente, a flutuação característica associada à produção de máquinas e equipamentos, sob o domínio da financeirização, vincula-se mais profundamente aos movimentos financeiros de formação dos estoques de riqueza em geral.

No caso brasileiro, não existem dados divulgados para o balanço das famílias, o que dificulta a estimação de seu grau de financeirização. No processo de financeirização das famílias, existem nexos entre estoques de riqueza, endividamento e consumo. Os trabalhos de Belluzzo e Coutinho (1998) e Palley (1994) e (1996) reconhecem a evidência que nos países desenvolvidos, ao longo dos anos 1980 e 1990, as classes médias ${ }^{10}$ constituíram importantes carteiras de ativos, incluídos bens imóveis e bens duráveis. 0 endividamento familiar crescente estimula a demanda agregada mediante a transferência do poder de compra das famílias de alta renda, com baixa propensão marginal a consumir, para famílias com baixa renda e alta propensão a consumir. Entretanto, tal mecanismo acaba se tornando um mecanismo perverso de redistribuição de renda, pois o ônus das dívidas assim contraídas sobre a demanda agregada tende a gerar um sobre-endividamento nas famílias de menores rendimentos. Essa situação fortalece 0 argumento da pertinência da razão entre estoques como medida mais apropriada de financeirização.

\footnotetext{
${ }^{9}$ Tal aspecto suscitou uma controvérsia a partir de um artigo de Arida (2003), mobilizando um debate sobre a "conversibilidade" da moeda nacional com outros economistas brasileiros. Todavia, seu teor não cabe ser levado em conta no presente artigo, cujo propósito não entra no mérito desta questão. Ressalta-se aqui apenas seu argumento do viés para "cima" para a estrutura das taxas de juros a longo prazo brasileiras.

${ }^{10}$ Esse campo é ainda aberto para alguns países emergentes com "classes médias" expressivas. Estudos posteriores, com base na recente construção de contas patrimoniais na contabilidade social brasileira, poderiam colaborar enormemente nesse sentido.
} 
No âmbito das empresas, pode-se recorrer aos balanços publicados, mas como 0 foco da análise aqui proposta é fundamentalmente macroeconômico, não serão utilizados indicadores para esse segmento, deixando-se os mesmos para trabalhos futuros que abordarão os indicadores micro e setoriais de financeirização. No entanto, este indicador expressa de forma agregada 0 estoque de ativos financeiros de famílias e empresas como proporção do estoque total de capital fixo produtivo. Trata-se de medir o volume de capital financeiro por unidade de capital imobilizado nas atividades diretamente produtivas.

\section{Metodologia de construção do indicador}

A taxa de financeirização é calculada pela razão entre 0 total de ativos financeiros não monetários (AF) e 0 estoque total de capital fixo produtivo (K). As séries do estoque de capital fixo são as publicadas pelo IPEADATA e permitem a separação entre 0 estoque produtivo e o residencial. Como o objetivo principal da construção de indicadores macroeconômicos de financeirização é justamente analisar os impactos desse fenômeno sobre o comportamento da acumulação de capital fixo produtivo - base do crescimento econômico - 0 indicador proposto utilizará o estoque de capital fixo em máquinas e equipamentos mais construções não-residenciais em vez do estoque total de ativos reais.

0 estoque de ativos financeiros é calculado indiretamente pela diferença entre os agregados monetários M4 e M1, que corresponde ao total de ativos financeiros não monetários da economia brasileira. 0 montante da diferença M4-M1 inclui, portanto, os títulos privados, títulos públicos, aplicações em poupança e demais ativos financeiros em poder dos agentes econômicos, incluindo os que funcionam como quase-moeda ou como moeda financeira, dada a sua alta liquidez e rentabilidade real.

0 Gráfico 2 descreve a taxa de financeirização e a taxa de acumulação de capital fixo produtivo para o período 1970-2010. Esta última foi calculada pela razão entre o fluxo de investimento (formação bruta de capital fixo) e 0 estoque de capital fixo produtivo estimado para os anos de 2009 e 2010. De sua análise, podem ser constatados dois períodos distintos pelos padrões de evolução das duas variáveis plotadas:

1. Entre 1970 e 1993, as séries da taxa de financeirização e de acumulação de capital fixo produtivo apresentam-se positivamente correlacionadas, expressando 0 fato de que ainda não existiam, àquela época, as condições estruturais para o desenvolvimento do processo de financeirização tal qual 0 vigente atualmente na economia brasileira. As poupanças familiar e empresarial são alocadas em sua forma diretamente produtiva, contribuindo para elevar as taxas de investimento; 


\section{Gráfico 2 Financeirização e acumulação de capital fixo produtivo (1970-2010)}

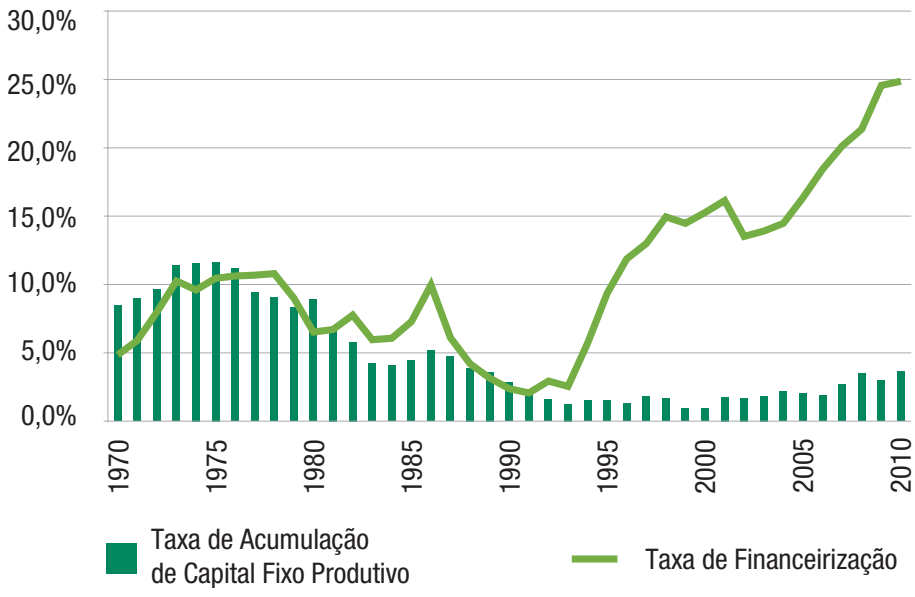

2. No período 1994-2010, a razão ativos financeiros/ativos fixos produtivos descola-se rapidamente da taxa de acumulação de capital. Isto é uma expressão característica dos processos de financeirização. Neste contexto, os capitais encontram fácil e rapidamente os canais institucionais para revalorizar-se através da ampla gama de ativos financeiros de alta rentabilidade e liquidez que uma economia financeirizada oferece, com garantias do Estado. Entre outras consequências macroeconômicas adversas, observa-se queda substancial do investimento em capital fixo produtivo e, em seguida, sua permanência em níveis historicamente muito baixos e inadequados à continuidade do processo de desenvolvimento econômico. Isso decorre do fato de que a financeirização eleva rapidamente 0 custo e os riscos inerentes às imobilizações de capital, que são, contudo, necessárias ao crescimento econômico e à geração de emprego e de renda.

Outra maneira de se considerar esse processo é mostrada no Gráfico 3, em que estão plotados 0 crescimento acumulado do estoque de ativos financeiros na economia brasileira, juntamente com o crescimento acumulado do estoque de capital fixo produtivo (os dois componentes desagregados da taxa de financeirização) e da taxa Seııc real. Destaca-se a forte correlação positiva entre o crescimento do estoque de ativos financeiros e a taxa Seuc real acumulada no mesmo período 1991-1999.

Deve-se considerar que essas duas variáveis evoluem em função de duas formas distintas de alocação das poupanças empresarial e familiar. 


\section{Transformações no padrão de financeirização: da "hiperinflação" ao "hiperjuro"}

Perspectivas históricas e institucionalistas tornam-se necessárias para se analisar 0 modo como as estruturas que suportam a acumulação rentista-patrimonial estão associadas a padrões diferentes de financeirização. No Gráfico 4, foram plotadas as séries do valor adicionado financeiro como percentagem do PIB e a taxa de inflação anual, para o período 1947-2010. Ambos os eixos estão em logaritmos das variáveis.

Três padrões de relacionamento entre essas duas variáveis se contrastam no tempo histórico em referência. Entre 1947 e 1969, as taxas de inflação eram baixas e o sistema financeiro brasileiro era por demais incipiente para permitir que a acumulação bancária e financeira pudessem desenvolver-se com base nas receitas inflacionárias. Apesar da criação, em 1964, do dispositivo institucional da correção

Gráfico 3 Expansão dos ativos financeiros, dos ativos reais e das taxas de juros básicas da economia brasileira (1991-2009)

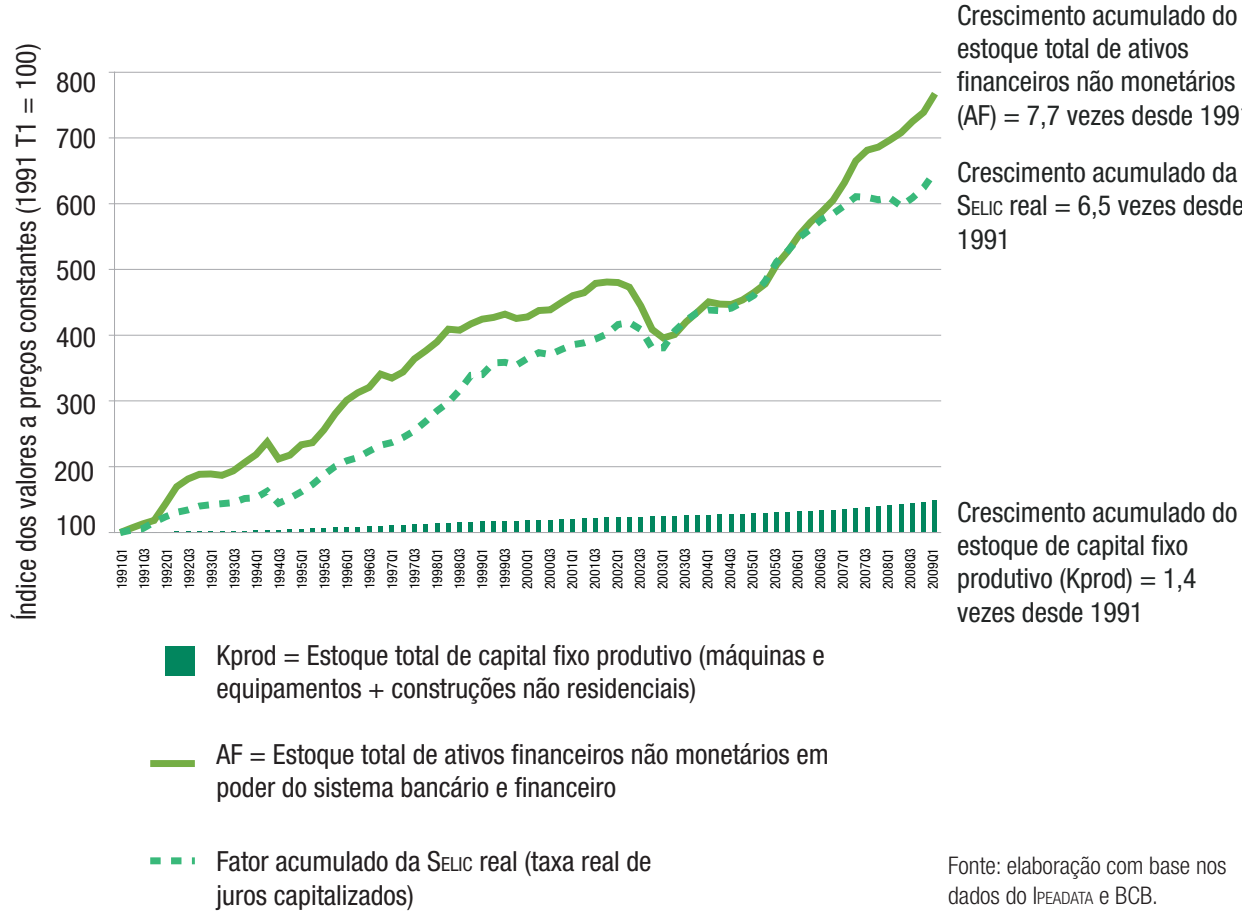


monetária, esse mecanismo ainda não tinha se generalizado e permanecia restrito à oferta de títulos da dívida pública.

A conjuntura macroeconômica dos anos de 1980 mostrou-se extremamente adversa para 0 desenvolvimento brasileiro, fazendo com que esse período ficasse conhecido na literatura econômica como a "década perdida." Todavia, essa mesma conjuntura mostrou-se muito benéfica à acumulação rentista-financeira mediante os chamados ganhos inflacionários.

A partir de 1995, com a estabilidade de preços, os ganhos inflacionários declinaram rapidamente, levando à queda progressiva da participação do setor bancário-financeiro no PIB, aferida pelo indicador do SIFIM. Se essa estatística refletisse adequadamente 0 grau de financeirização da economia, por consequência, esse fenômeno teria se enfraquecido com a queda das taxas de inflação. Em suma, essa estatística não é uma medida correta do grau de financeirização de uma economia, pois como computa apenas a parcela apropriada pelas empresas financeiras, pouco revela sobre a cota que caberia às empresas não financeiras e às famílias, exatamente os setores relevantes para se estimar o grau de financeirização.

Os elevados níveis das taxas de juros praticadas na economia brasileira têm sido objeto de inúmeros debates, muitas das vezes com argumentos tautológicos, como aqueles que buscam explicações no risco-país ou em problemas estruturais

\section{Gráfico 4 Regimes monetários e padrões de financeiriz ação no Brasil (1947-2010)}

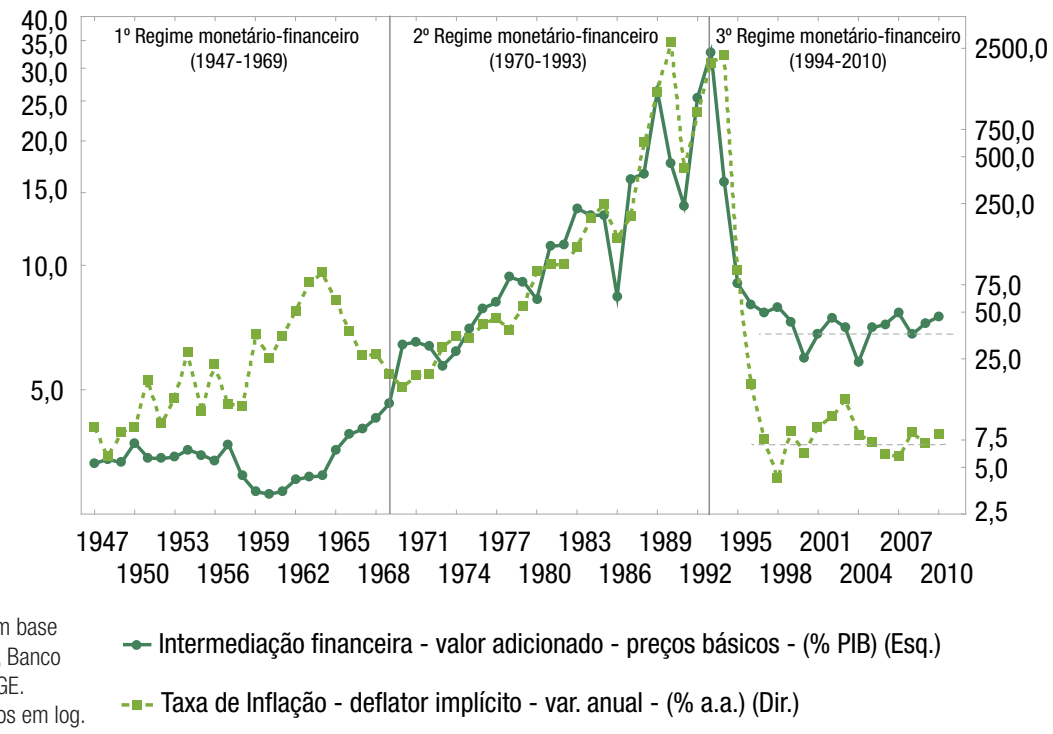


típicos de países não desenvolvidos. Ora, sabe-se que existem países também em desenvolvimento com graves problemas estruturais, mas onde as taxas de juros permanecem significativamente abaixo das do Brasil.

A Economia Política Clássica fornece exemplos que são úteis à uma abordagem alternativa, fora portanto do pensamento econômico convencional, que, em geral, está preso a conceitos e hipóteses que se convertem em verdadeiros obstáculos epistemológicos. ${ }^{11}$ Um exemplo notável é 0 da análise ricardiana da renda da terra, pois é capaz de mostrar como a distribuição setorial do excedente econômico termina afetando 0 ritmo de acumulação de capital e de crescimento econômico. Nesse contexto, Ricardo mostra como a apropriação crescente da renda da terra por parte dos proprietários fundiários levaria a uma baixa da taxa de lucro no setor industrial, em razão da elevação dos preços agrícolas.

\section{Gráfico 5 Taxas de juros reais brasileiras permanecem muito acima} dos padrões internacionais (1995-2008)

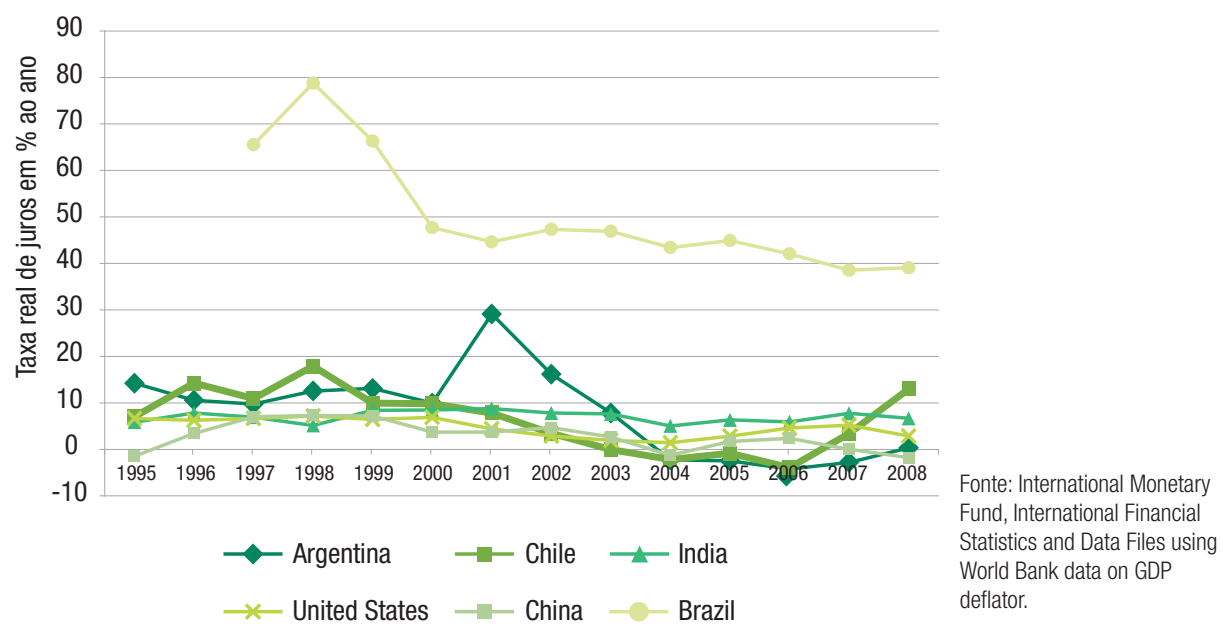

${ }^{11} 0$ conceito de obstáculo epistemológico foi proposto por Bachelard, em A Formação do Espirito Cientifico (1938), e se refere também a práticas de pesquisa, definições conceituais e hipóteses de análise para os quais o pesquisador tem grandes resistências em abandonar, seja por influência cultural-ideológica, seja pela própria inércia criada pelas instituições de ensino e pesquisa ao reproduzirem, como é o caso em Ciências Econômicas, parte do saber convencional, de maneira doutrinária e acrítica. 


\section{0 estado na financeirização}

Estudos recentes explicitaram as condições estruturais através das quais esse processo se desenvolve. Um destaque especial tem sido dado à perda de autonomia do Estado em múltiplas dimensões: restrições quanto à formatação da política econômica; esvaziamento político de seus papéis nas estratégias de desenvolvimento econômico nacional; queda das taxas de poupança e do investimento do setor público; e rápido e persistente endividamento improdutivo, onerosamente financiado em termos de prazos e encargos. ${ }^{12}$

No caso brasileiro, o padrão de inserção internacional tem se constituído em um elemento-chave para se compreender a natureza do regime fiscal num contexto

Tabela 7 Detentores de Títulos Públicos Federais - em (\%) (1999-2012)

\begin{tabular}{cccccc} 
Ano & Famílias & $\begin{array}{c}\text { Empresas } \\
\text { Não financeiras }\end{array}$ & $\begin{array}{c}\text { Empresas } \\
\text { Financeiras }\end{array}$ & $\begin{array}{c}\text { Fundos } \\
\text { de Investimento }\end{array}$ & Total Cliente \\
\hline 1999 & 0,90 & 17,78 & 3,07 & 78,25 & 100,00 \\
\hline 2000 & 0,90 & 16,25 & 2,93 & 79,92 & 100,00 \\
\hline 2001 & 1,08 & 13,53 & 2,23 & 83,16 & 100,00 \\
\hline 2002 & 1,89 & 16,05 & 2,04 & 80,02 & 100,00 \\
\hline 2003 & 0,32 & 15,28 & 1,11 & 83,29 & 100,00 \\
2004 & 0,29 & 10,99 & 1,20 & 87,52 & 100,00 \\
\hline 2005 & 0,30 & 10,44 & 0,85 & 88,41 & 100,00 \\
\hline 2006 & 0,29 & 10,96 & 0,11 & 88,64 & 100,00 \\
\hline 2007 & 0,35 & 15,00 & 1,64 & 83,01 & 100,00 \\
2008 & 0,53 & 18,27 & 4,87 & 76,33 & 100,00 \\
2009 & 0,83 & 18,64 & 5,79 & 74,74 & 100,00 \\
\hline 2010 & 0,85 & 17,55 & 9,74 & 71,86 & 100,00 \\
2011 & 1,11 & 15,03 & 11,30 & 72,56 & 100,00 \\
2012 & 1,30 & 14,02 & 12,42 & 72,26 & 100,00 \\
\hline
\end{tabular}

Fonte: Banco Central do Brasil, 2012.

\footnotetext{
${ }^{12} 0$ endividamento improdutivo refere-se ao aumento da dívida pública decorrente da emissão de novos títulos para financiar a dívida passada. Basicamente, consiste na rolagem da dívida pública sem impactos positivos nas finanças públicas e no crescimento econômico. Por outro lado, o endividamento produtivo ocorre quando a dívida pública se expande para financiar o investimento do governo, por exemplo, em infraestrutura. Nesse último caso, ocorrerá aumento do estoque de riqueza da sociedade com impactos positivos na geração de emprego e de renda, resultando no longo prazo, na queda tendencial da razão dívida pública/PIB.
} 
de finanças liberalizadas e de acumulação rentista. Nesse padrão de inserção internacional, com mercado de derivativos profundo e ausência de controles de capitais, a taxa de câmbio integra-se às carteiras de ativos financeiros considerados fundamentais à revalorização rentista dos capitais especulativos e de curto prazo. Daí a grande dificuldade para o País dispor de taxas de juros internas e de câmbio compatíveis com as necessidades das atividades diretamente produtivas, pois tais condições estariam em contradição com os mesmos pressupostos do modelo econômico vigente.

A viabilidade macroeconômica desse modelo, ou seja, suas condições de reprodução, exige que 0 Estado se converta em fiador de um processo de abertura financeira que o restringe significativamente quanto à formatação da política econômica. Apesar de seu elevado custo de carregamento, a rápida acumulação de reservas internacionais torna-se estratégica à continuidade desse modelo. No entanto, tal processo se dá predominantemente por meio da entrada de capitais especulativos e muito menos pelo potencial exportador do País. A Tabela 7 mostra os detentores de títulos públicos federais. Depois dos fundos de investimento, que detêm a maior participação, as empresas não financeiras, em geral, estão muito acima da participação das empresas financeiras. 


\section{Considerações finais}

Há sempre uma alternativa à propriedade de capital real, notadamente, a propriedade de moeda e débitos. (Keynes)

0 fenômeno da financeirização da economia brasileira pode ser satisfatoriamente abordado, utilizando-se para tanto de indicadores macroeconômicos de relativa facilidade de construção. Trabalhos futuros podem propor 0 desenvolvimento de indicadores para os níveis micro e setorial, de maneira a complementar a análise aqui proposta.

No caso brasileiro, destaca-se a elevada participação da renda de juros no produto interno bruto, fato que singulariza o processo de financeirização da economia nacional, em comparação com outros países desenvolvidos e em desenvolvimento, nos quais as taxas de juros são muito mais baixas.

A financeirização reduz a eficiência dos gastos públicos e a capacidade de poupança e investimento do Estado. Dada a alternativa institucionalmente facilitada de alocação das poupanças empresariais e das famílias em ativos financeiros, a alocação diretamente produtiva fica comprometida. Em consequência, a taxa de acumulação de capital reduz-se e mantém-se num patamar insuficiente para garantir taxas mais elevadas e sustentáveis de crescimento econômico.

Nesse contexto, a própria formação endógena de poupança é prejudicada, uma vez que a financeirização implica o predomínio da poupança improdutiva em detrimento da poupança produtiva, ou seja, aquela que eleva a taxa de investimento, pois financia a formação bruta de capital fixo.

Os setores econômicos deficitários quanto ao fluxo de juros são as empresas não financeiras e a administração pública. Por outro lado, as famílias, as empresas financeiras e 0 resto do mundo apresentam-se superavitários no que concerne à renda de juros, isto é, recebem mais do que pagam. Poder-se-ia considerar que tais comportamentos sejam normais, porquanto as atividades produtivas e o governo serão os pagadores líquidos de juros e os demais setores de atividade econômica, recebedores líquidos. Porém, a questão fundamental refere-se à magnitude das taxas de juros que respondem por esses fluxos e pela oportunidade de participação neste tipo de renda financeira por parte das empresas não financeiras, que são 0 segundo maior detentor de títulos públicos federais.

Os fundos de investimento apresentam a maior participação na detenção dos títulos governamentais, fato que reduz sobremaneira a possibilidade de que essas instituições possam tornar-se agentes promotores do investimento produtivo e da formação de poupança de longo prazo para o País. Consequentemente, os discursos 
que enfatizam o papel dos investidores institucionais como agentes do desenvolvimento econômico se equivocam e não contribuem para a emergência de regimes de crescimento e acumulação de capital mais consentâneos com as necessidades do desenvolvimento socioeconômico brasileiro.

Do ponto de vista analítico, o estatuto teórico do conceito de financeirização deve ser reconhecido e a problemática que implica aprofundada, sobretudo, no que concerne às explicações satisfatórias para a permanência das baixas taxas de investimento na economia brasileira. Por outro lado, análises consistentes acerca das causas da crise global de 2008-2009, e os atuais desdobramentos, estariam melhor capacitadas para compreender a gênesis dessa crise se as mesmas incorporassem o processo de financeirização e suas principais consequências macroeconômicas no escopo teórico. 


\section{Referências}

AGLIETTA, Michel. Macroéconomie financière. vol 1 et 2, La Découverte, Paris, 2001. . La Crise. Pourquoi en est-on arrivé là ? Comment en sortir?

Éditions Michalon, 2008.

Álvarez, I. y Luengo, F. (2011): «Financiarización, acumulación de capital y crecimiento salarial en la UE-15», Investigación Económica, vol. LXX (276), pp. 125-162.

AMITRAN0, Claudio R. Regime de Crescimento, Restrição Externa e Financeirização: uma proposta de conciliação. Texto para Discussão 1612, IPEA, maio de 2011.

ARIDA, P. (2003). "Por uma moeda plenamente conversível". Revista de Economia Política, 23(3): 151-154 jul./set.

BECKER, Joachim. JÄGER, Johannes. LEUBOLT, Bernhard. WEISSENBACHER, Rudy. Peripheral Financialization and Vulnerability to Crisis: A Regulationist Perspective. competition and change, Vol. 14 №. 3-4, December, 2010, 225-47.

BOYER, Robert. Deux défis pour le XX₹ siècle: discipliner la finance et organiser l'internationalisation. CEPREMAP ${ }^{\circ}$ 2000-08, Paris, 2000.

Is a finance-led growth regime a viable alternative to Fordism? A preliminary analysis. Economy and Society. Volume 29 number 1 february 2000. . La politique a l'ere de la mondialisation et de la finance: le point sur quelques recherches regulationnistes. CEPREMAP, Paris, 1999.

BRAGA Souza [1998], Financeirização global: o padrão sistêmico de riqueza do capitalismo contemporâneo, in Tavares, Eds, "Poder e dinheiro", Editora Vozes, $6^{\text {a }}$ edição, p-195/242.

BRASIL. (2010) Uma Estratégia Inovadora Alavancada pela Renda. Organização Internacional do Trabalho- OIT.

BRUNO Miguel, HALEVI Joseph, MARQUES PEREIRA Jaime «Les défis de l'influence de la Chine sur le développement du Brésil» (pages 83 à 102), Revue Tiers Monde $n^{\circ} 208$ (4/2011).

BRUNO, M. Acumulação de Capital e Crescimento Econômico no Brasil: uma análise do período 1950-2006. in SICSÚ. J, Miranda. P (2009) (org.) Crescimento Econômico: Estratégias e Instituições Ed: IPEA. Rio de Janeiro.

BRUNO, M.; ARAÚJO, E. DIAWARA, H.; REIS, Ana Carolina. S. e RUBENS, M. Finance-led growth no Brasil: estatuto teórico, evidências empíricas e consequências macroeconômicas. Texto para Discusão nº 1455, Brasília, Dezembro, 2009. 
CHESNAIS, François. La théorie du régime d'accumulation financiarisé: contenu, portée et interrogations. Forum de La Régulation, Paris, 2003.

COUTINHO \& BELLUZZO. "Financeirização" da Riqueza, Inflação de Ativos e Decisões de Gasto em Economias Abertas. Economia e Sociedade, 11: p.137-150, 1998.

EPSTEIN, Gerald. Financialization, rentier interests and Central Bank Policy. PERI Conference on "Financialization of the World Economy", December, 2001.

EPSTEIN, Gerald. et al. Financialization and the World Economy. Elgar Cheltenham, UK Northampton, MA, USA, 2005.

FRÉZAL, Sylvestre. Modèles et mesures. Éléments d'épistémologie économique, Ellipse, 2010.

GRAMSCI, Antonio. Cadernos do Cárcere. V. 1, edição e tradução de Luiz Sérgio Henriques; co-edição, Carlos Nelson Coutinho e Marco Aurélio Nogueira. 4 ed. Rio de Janeiro: Civilização Brasileira, 2006.

GUTTMANN, Robert. A Primer on Finance-Led Capitalism and Its Crisis. Revue de la régulation Capitalisme, Institutions, Pouvoirs, $n^{0}$ 3/4, 2008.

HEIN, E. (2010), 'Shareholder value orientation, distribution and growth - short-and medium- run effects in a Kaleckian model', Metroeconomica, 61, 302-332.

HEIN, E. (2011), 'Financialisation', distribution and growth, in A Modern Guide to Keynesian Macroeconomics and Economic Policies, (Editors, Eckhard Hein, Engelbert Stockhammer), Cheltenham: Edward Elgar.HEIN, E. The Macroeconomics of Finance-dominated Capitalism - and its Crisis. Edward Elgar Cheltenham, UK Northampton, MA, USA, 2012.

HEIN, E. and L. VOGEL (2008). Distribution and growth reconsidered: empirical results for six OECD countries, Cambridge Journal of Economics, 32 (3), 479-511. Ideology for Corporate Governance." Economy and Society 29(1): 13-35.

HUSSON, M. Un pur capitalisme, Lausanne, Page Deux, 2008.

KALDOR, N. Capital Acumulation and Growth in: The Essential Kaldor. (org.) Targetti, F. e Thirlwall, A.P. 1989c. New York. Holmes \& Meier Publishers, Inc., 1989b.

. Alternative Theories of Distribution in: The Essential Kaldor. (org.)

Targetti, F. e Thirlwall, A.P. New York. Holmes \& Meier Publishers, Inc.,1989a.

KALECKI, M. (1997). Teoria da Dinâmica Econômica: Ensaio Sobre as Mudanças Cíclicas e a Longo Prazo da Economia Capitalista. ED. Nova Cultural São Paulo.

. Algumas observações sobre a teoria de Keynes, in Clássicos de literatura econômica: textos selecionados. Editora IPEA, 2010.

KLIMAN, A. WILLIAMS S. D.. "Why “Financialization” Hasn't Depressed U.S. Productive Investment." Paper presented at Association for Heterodox Economics 
Conference, Paris, 2012.(http://www.assoeconomiepolitique.org/politicaleconomy-outlook-for-capitalism/? $\mathrm{p}=227$ ).

KRIPPNER, Greta R. The financialization of the American economy, Socio-Economic Review, 173-208, 2005.

LAZONICK, W. e 0'Sullivan, M. (2000). Maximizing Shareholder Value: A New Ideology for Corporate Governance', Economy and Society, 29.

MARQUETTI, Adalmir. The rate of profit in the Brazilian economy 1953-2003, in Actuel Marx, Paris, 2005.

ORHANGAZI, Özgur. Financialisation and capital accumulation in the non-financial corporate sector. A theoretical and empirical investigation on the US economy: 1973-2003. Cambridge Journal of Economics 1 of 24, 2008.

PALLEY, Thomas. Financialization: what it is and why it matters. Working Papers $\mathrm{n}$. 525, The Levy Economics Institut of Bard College. December, 2007.

PAULANI, Leda. A crise do regime de acumulação com dominância da valorização financeira e a situação do Brasil. Estudos Avançados, 23 (66) 2009.

SKOTT, Peter and RY00, Soon. Macroeconomic Implications of financialization. University of Massachusetts Amherst, Department of Economics, Working Paper 2007-08, 2007.

STOCKHAMMER, E. Some stylized facts on the finance-dominate accumulation regime. Political Economy Research Institut - PERI - University of Massachussets Anherst, 2.

Financialization and the slowdown of accumulation.

Cambridge Journal of Economics, n. 28, p. 719-741, 2004.

STOCKHAMMER, E. and Ö. ONARAN (2004), Accumulation, distribution and employment: a structural VAR approach to a neo-Kaleckian macro-model, Structural Change and Economic Dynamics, 15 (4), 421-47.

TOBIN, J. (1997). 'Is low saving an Overrated Problem?', in Pollin, R. (ed.), The Macroeconomics of Savings, Finance and Investment, Ann Arbor, University of Michigan Press. VAN TREECK, T. (2009), 'A synthetic stock-flow consistent macroeconomic model of financialisation', Cambridge Journal of Economics, 33, 467-493. 
